\title{
Pathology of Lupus Nephritis with Special Reference to the Immunological Bases of Glomerular Changes*
}

\author{
Teruo Fujimoto and Takanobu Kitamura \\ Department of Pathology $\dagger$, Osaka City University Medical School, \\ Osaka 545
}

\begin{abstract}
Fujimoto, T. and Kitamura, T. Pathology of Lupus Nephritis with Special Reference to the Immunological Bases of Glomerular Changes. Tohoku J. exp. Med., 1977, 122 (4), 355-374_ Glomerular changes, and cellular and tissue responses of antibody-forming organs in 37 eases $(20$ cases with nephrotic syndrome and 17 cases without the syndrome) of systemic lupus erythematosus (SLE) were described. The glomerular changes were classified into 3 types, i.e., proliferative glomerulitis, membranous transformation, and wire-loop lesion from the standpoint of glomerular functional structure and its alterations. As to the responses of antibody-forming organs, hypoplasia of myeloid tissue, atrophy of lymph follicles of spleen and lymph nodes, atrophy and decrease in numbers of lymphocytes of thymus, proliferation and infiltration of plasma cells and plasmocytoid basophilic mononuclears, and proliferation of basophilic reticulum cells at the cost of differentiated antibody-forming organ tissues of bone marrow, spleen, lymph nodes, etc. were noted. Immunological bases of glomerular changes were considered and discussed in the light of pathological findings of SLE presented here and suggestions from experimental pathological studies in this field. Pathogenic roles of antigen-antibody complexes as well as anti-glomerular basement membrane (anti-GBM) antibody were considered in relation to the histologic manifestations of glomeruli in SLE or lupus nephritis.

systemic lupus erythematosus; glomerulonephritis; nephrotic syndrome; auto. immune disease; immune complex disease
\end{abstract}

Klemperer et al. (1941) first presented a detailed description of pathological changes of disseminated lupus erythematosus, and introduced a new idea into the understanding of this disease that disseminated lupus erythematosus is not a mere cutaneous lesion but a systemic disease as was later called systemic lupus erythematosus (SLE). Since that time, such pathologic changes as renal lesions including wire-loop glomerular lesion, onion-skin lesion of spleen, Libman-Sacks endocarditis, cutaneous lesions, i.e., disseminated lupus erythematosus, hematoxylin bodies,

Received for publication, March 7, 1977.

* This study was supported by a Research Grant from the Intractable Diseases Division, Public Health Bureau, Ministry of Health and Welfare, Japan, and parts of this paper were presented at the 63rd Annual Meeting of the Japanese Pathological Society, April 3, 1974, Nagoya, and at the 64th Annual Meeting, April, 3, 1975, Takatsuki.

† Director: Prof. T. Fujimoto.

Mailing address: T. Fujimoto, M.D., Department of Pathology, Osaka City University

Medical School, Asahi-machi, 1-4-54, Abeno-ku, Osaka, 545 Japan. 
etc. have been generally accepted and interpreted as pathognomonic of this disease (Klemperer 1952). It has been well known that the majority of cases of SLE are clinically characterized by urinary abnormality and derangement of renal function, and concerning the renal lesions many contributions have been brought about from the studies by means of light and electron microscopical observations as well as fluorescent antibody technique (Pollak et al. 1966). As to the pathogenesis of SLE, attentions have been paid upon the formation of auto-antibody and its pathogenic role in the occurrence of cellular and tissue changes, and there have been accumulating data obtained from studies of spontaneous animal diseases resembling SLE in man (Howie and Helyer 1968; and others), but cellular and tissue responses of antibody-forming organs in SLE have not been thoroughly elucidated. Recently, it was pointed out that SLE is an immune-complex disease (Koffler et al. 1971). Pathogenesis of renal lesions in SLE, however, appears not so simple as might be merely interpreted as an immune-complex nephritis.

It is the purpose of this paper to describe the pathological findings of SLE, especially glomerular changes and cellular and tissue responses of antibody-forming organs, and consider and discuss the immunological bases of glomerular lesions in this disease.

\section{Materials and Methods}

The materials examined here were 37 cases of SLE which were collected from the Departments of Pathology of Osaka City University Medical School (4 cases), Chiba University School of Medicine (9 cases), Toshima Hospital, Tokyo (1 case), Sapporo Medical College (3 cases), Muroran Municipal Hospital, Hokkaido (1 case), and Niigata University School of Medicine (19 cases). According to the diagnostic criteria for SLE of Pollak et al. (1966), these 37 cases were classified into 21 cases with 4 or more major criteria, 9 cases with 3 major plus 2 or more minor criteria, and 7 cases with 2 major plus 3 or more minor criteria. Among the 37 cases, 20 cases (Group I) had nephrotic syndrome (albuminuria of more than $3.5 \mathrm{~g} /$ day, hypoproteinemia of less than $6.0 \mathrm{~g} / 100 \mathrm{ml}$, serum total cholesterol level of more than $250 \mathrm{mg} / 100 \mathrm{ml}$, and edema) (Table 1), while 17 cases (Group II) did not have this syndrome (Table 2). In the Group I, duration of SLE ranged from 2 months to 8 years, that of renal diseases from 20 days to 6 years plus 1 month, and that of nephrotic syndrome from 10 days to 5 years plus 3 months. Eleven cases out of 20 had azotemia. Among the 18 cases treated with steroid therapy, 4 showed transitory remission, 4 had some exacerbation, and the others were not influenced. In the Group II, duration of SLE ranged from 50 days to 5 years, and that of renal diseases (14 cases) from 0.5 month to 4 years plus 10 months. Among these 14 cases with renal diseases, 1, 5, and 4 cases had azotemia, moderate hypoproteinemia, and moderate albuminuria, respectively. Histological sections from kidneys, bone marrow (sternum, vertebra, etc.), spleen, lymph nodes (paratracheal, bronchopulmonary, lumbar, mesenteric, etc.), liver, thymus, and other various organs of these 37 cases were treated with hematoxylin and eosin stain (HE, stain), PAS stain, PAM stain, Mallory-Heidenhain stain, PTAH stain, silver impregnation, Feulgen reaction, Unna-Pappenheim stain, ete, and examined light microscopically.

\section{RESUlts}

\section{Glomerular changes}

In the kidneys of SLE with nephropathy, various characteristic glomerular lesions were noted. They were endothelial cell proliferation, focal necrosis, 
Pathology of Lupus Nephritis

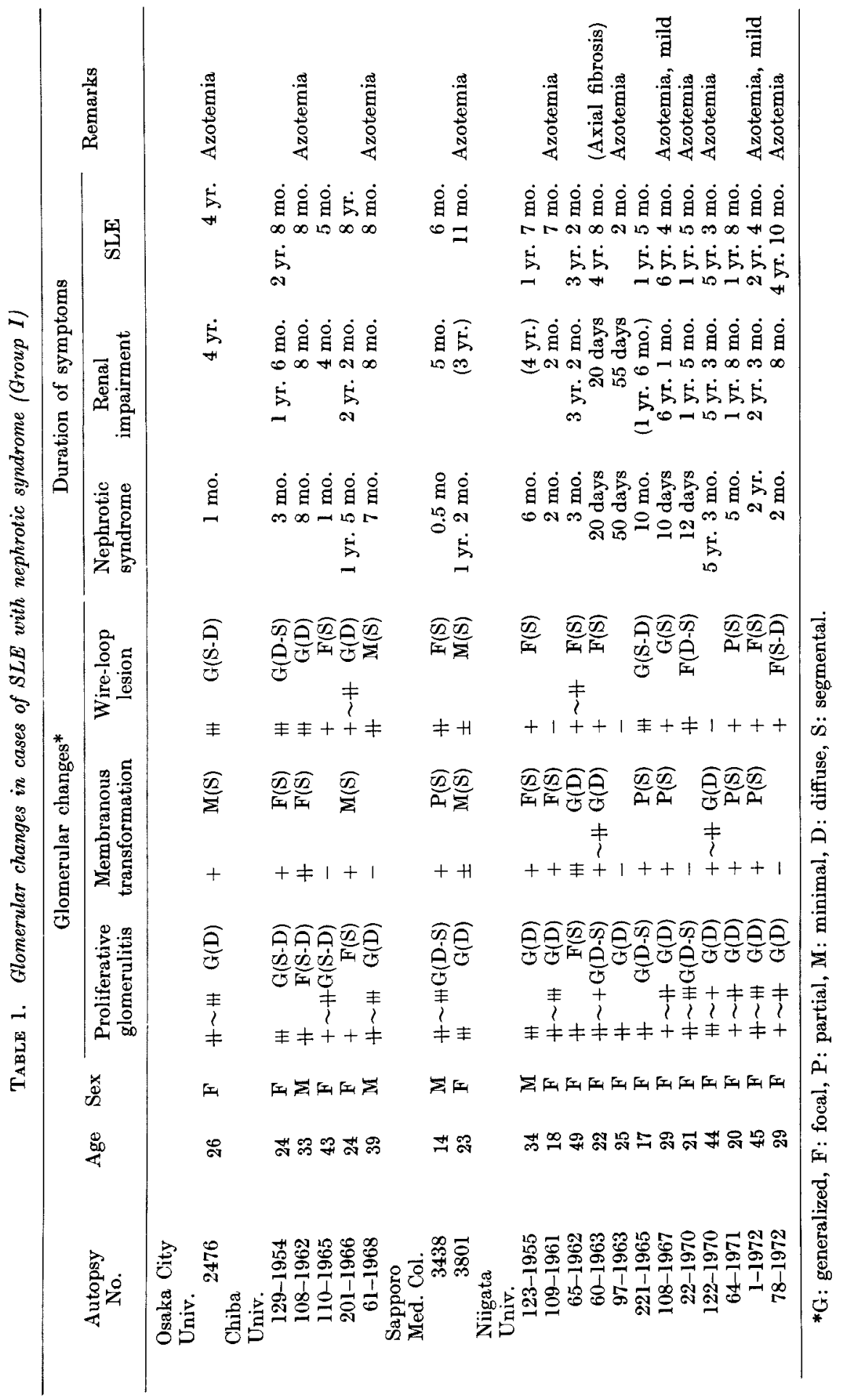




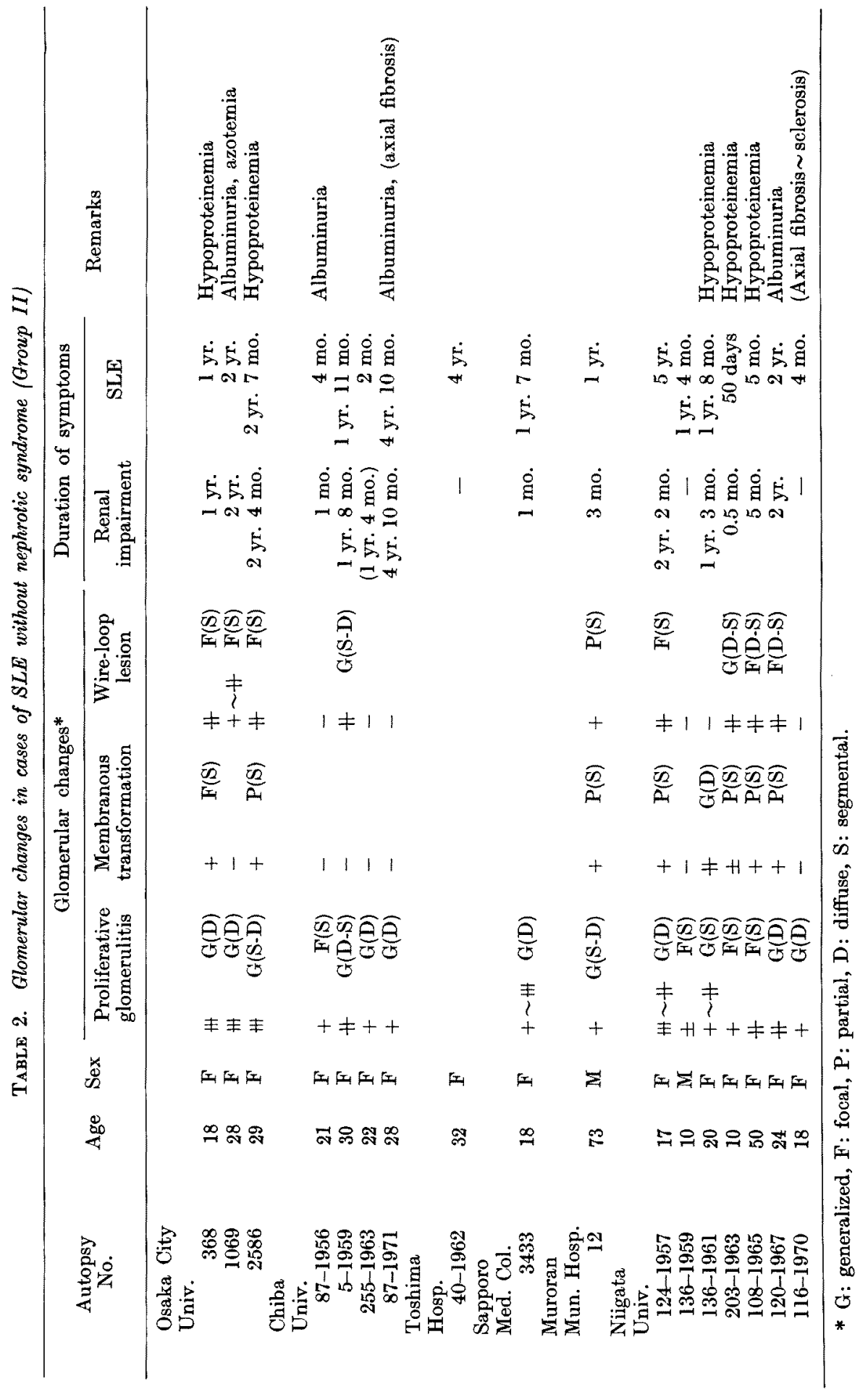


fibrinoid degeneration and thickening of loop wall (wire-loop lesion), karyorrhexis, formation of hematoxylin body, hyaline or fibrinoid thrombi not infrequently mingled with hematoxylin-stained materials, etc. Among the glomerular changes, proliferative glomerulitis, membranous transformation, and wire-loop lesion were most remarkable from the point of view of glomerular functional structure and its alterations.

(1) Proliferative glomerulitis: Glomerular loops were enlarged, anemic, and transformed into reticular structure due to proliferation of fixed cells mainly of endothelial origin which were connected with their cytoplasmic processes (Fig. 1). The loops contained some polymorphonuclear leukocytes and occasional monocytes. In some cases, these proliferated cells accumulated or crowded towards axis of the loop, accompanying formation of fibrils or fibers along them, and recanalization occurred in the periphery of the loop (axial fibrosis). Sclerosis of mesangial or axial tissue of the loop with preserved capillary structure following mild cellular proliferation of glomeruli (axial sclerosis) was also encountered.

(2) Membranous transformation: Capillary structure of glomerular loop was well preserved, and predominant lesion lay in thickening of loop walls due to subepithelial deposition of eosinophilic material not infrequently accompanied by hematoxyphil tint (Fig. 2). PAS and PAM stains revealed spiky projections of basement membrane towards glomerular epithelial side which were enclosed and overlaid by the subepithelial deposits (Fig. 3). In the advanced stage, there occurred a new formation of basement membrane structure just beneath the epithelial cells, which fused with original basement membrane, forming a thicker basement membrane. In association with the lesions described above, mild endothelial proliferation was encountered, but not so frequently.

(3) Wire-loop lesion: Glomerular loops showed eosinophilic thickening of the walls (Fig. 4). Capillary structure was almost preserved, and main lesion was characterized by subendothelial deposition of fibrinoid material stained blue with PATH stain in capillary loop walls, which was most distinctly revealed by PAM staining (Fig. 5). In these loops some endothelial reaction was noted, but not constantly.

The distribution of these glomerular lesions was not always so diffuse or widespread as in the sense of diffuse glomerulonephritis. Accordingly, it appears important to describe the distribution of glomerular lesions especially in understanding the correlation between glomerular changes and nephrotic syndrome. The modes of distribution of glomerular lesions are classified into the following 6 patterns.

(1) Generalized: The same kind of glomerular lesion is recognized throughout the kidney or in all or almost all of glomeruli in a section.

(2) Focal: A lesion appears in less than half the number of glomeruli.

(3) Partial: A lesion is encountered only in about 10 per cent of glomeruli.

(4) Minimal: A kind of glomerular lesion appears in only 1 or 2 glomeruli.

(5) Diffuse: The same kind of lesion is seen in all or almost all loops of a glomerulus.

(6) Segmental: The same kind of lesion is recognized in less than half the loops of a glomerulus.

In Group I, 13 cases had severe, generalized, and diffuse glomerular lesions Table 1). Among the 20 cases, combination or coexistence of 3 types of ylomerular lesions was found in 9 cases (Figs. 6, 7, and 8), while that of 2 types of ylomerular lesions in 5 cases. Predominance of proliferative glomerulitis was noted 


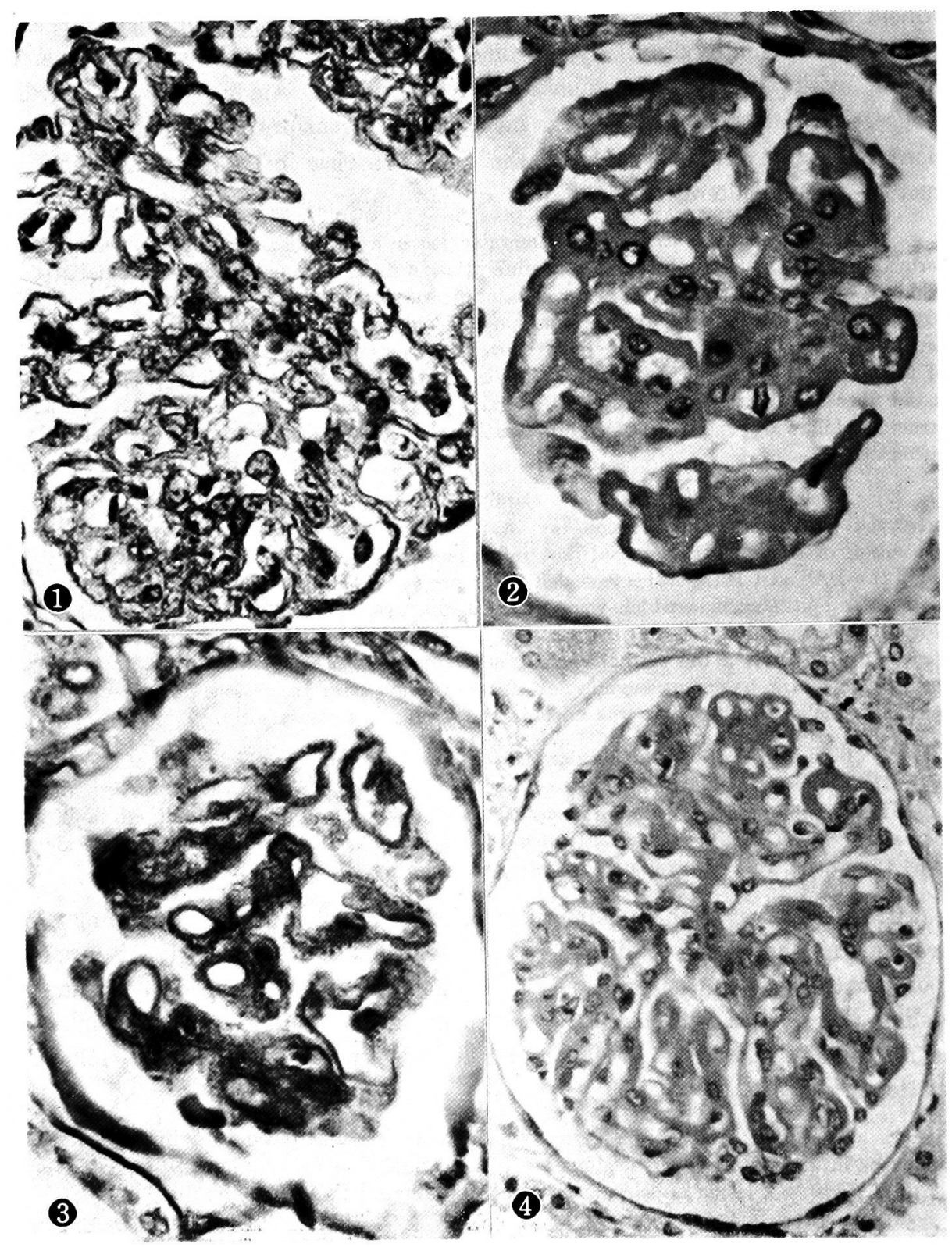

Fig. 1. Proliferative glomerulitis. Niigata Univ. 221-1965. PAM stain. $\times 600$.

Fig. 2. Membranous transformation. Niigata Univ. 65-1962. HE stain. $\times 600$.

Fig. 3. Membranous transformation. Niigata Univ. 65-1962. PAM stain. $\times 600$.

Fig. 4. Wire-loop lesion. Niigata Univ. 203-1963. HE stain. $\times 300$.

in 3 cases, that of membranous transformation in 1 case, and that of wire-loop lesion in 2 cases. In Group II, 14 cases of renal impairment showed severe to mild glomerular lesions, which were generalized and diffuse in 11 cases, and focal and 


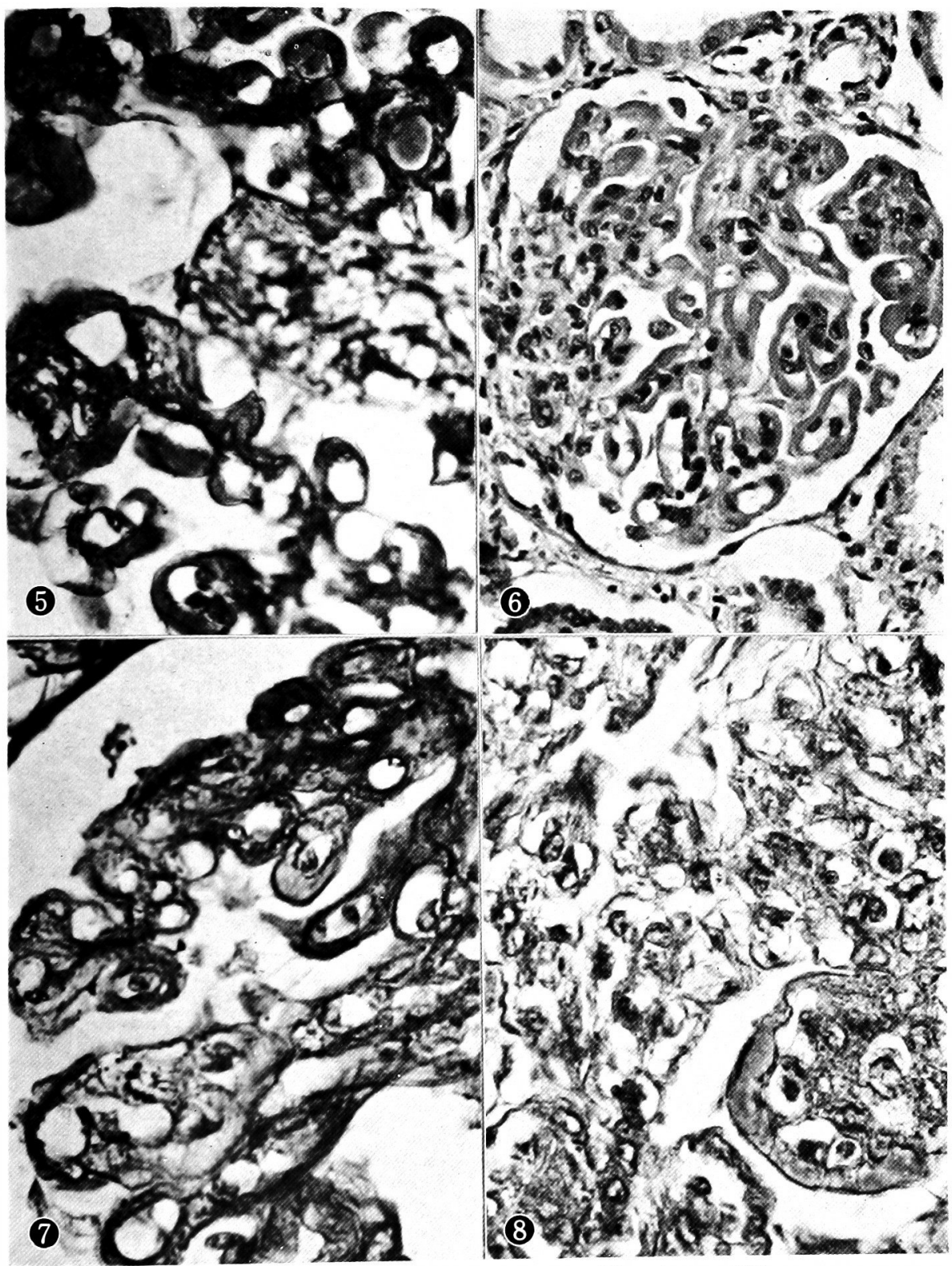

Fig. 5. Wire-loop lesion. Niigata Univ. 108-1965. PAM stain. $\times 600$.

Fig. 6. Concurrence of proliferative glomerulitis, membranous transformation, and wireloop lesion. Chiba Univ. 129-1954. HE stain. $\times 300$.

Fig. 7. Coexistence of membranous transformation and wire-loop lesion. Chiba Univ. 1291954. PAM stain. $\times 600$.

Fig. 8. Concurrence of proliferative glomerulitis and wire-loop lesion. Nigata Univ. 2211965. PAM stain. $\times 600$. 


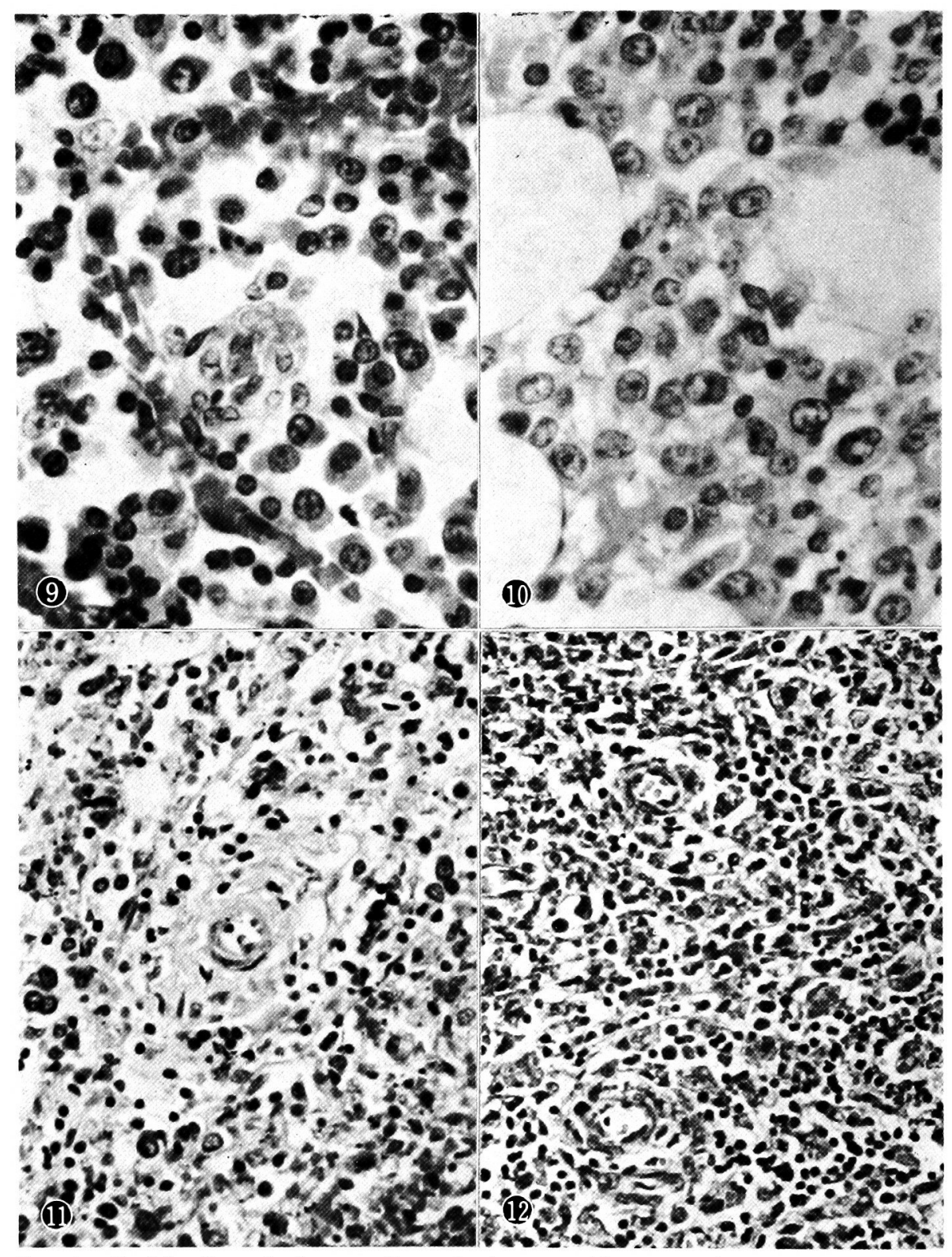

Fig. 9. Proliferation of plasma cells and plasmocytoid mononuclears in bone marrow (sternum). Sapporo Med. Col. 3433. HE stain. $\times 600$.

Fig. 10. Proliferation of reticulum cells in bone marrow (sternum). Niigata Univ. 1081965. HE stain. $\times 600$.

Fig. 11. Atrophy of splenic lymph follicle and appearance of basophilic mononuclears. Sapporo Med. Col. 3438. HE stain. $\times 300$.

Fig. 12. Atrophy of splenic lymph follicles and increase of reticulum cells with vesicular cytoplasms. Chiba Univ. 5-1959. HE stain. $\times 300$. 


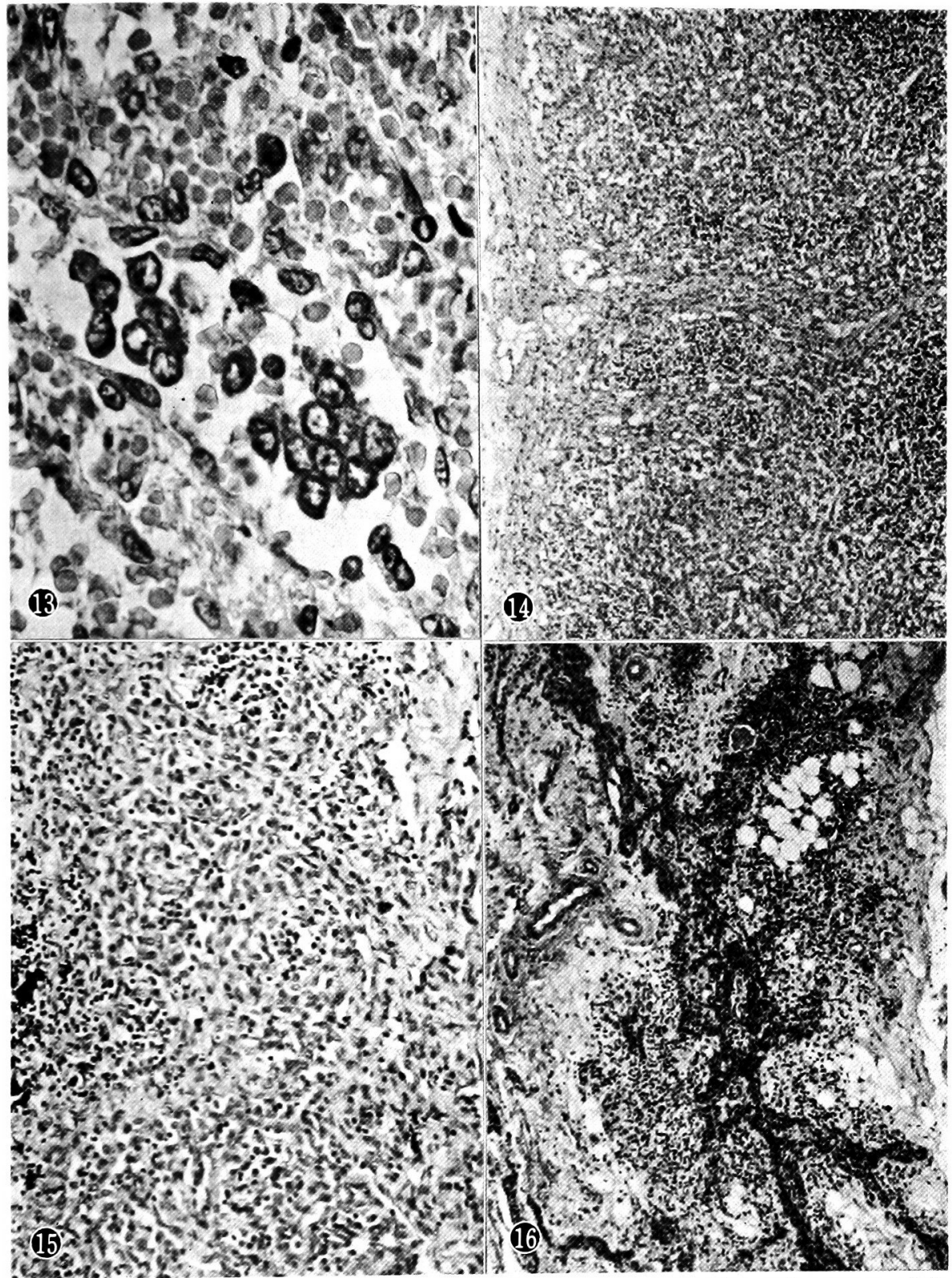

Fig. 13. Accumulation of atypical basophilic mononuclears in splenic sinus covered by basophilic, swollen endothelial cells. Niigata Univ. 78-1972. HE stain. $\times 600$

Fig. 14. Atrophy of lymph follicles and decrease of lymphocytes in deeper zones of cortex (lumbar lymph node). Niigata Univ. 78-1972. HE stain. $\times 60$.

Fig. 15. Atrophy of lymph follicles and proliferation of reticulum cells (paratracheal lymph node). Chiba Univ. 5-1959. HE stain. $\times 300$.

Fig. 16. Atrophy of thymus with decrease of lymphocytes. Sapporo Med. Col. 3438. $\mathrm{HE}$ stain. $\times 60$. 
segmental in 3 cases (Table 2). Five cases of moderate hypoproteinemia and 2 cases of moderate albuminuria demonstrated combination of 2 or 3 types of glomerular lesions, and residual 2 cases of moderate albuminuria consisted of 1 case having focal and segmental proliferative glomerulitis and 1 case showing generalized occurrence of axial fibrosis of glomerular loops. In the 3 cases without clinical manifestations of renal diseases, 1 had no glomerular lesions, and the other 2 had mild and segmental proliferative glomerulitis and axial fibrosis or sclerosis.

\section{Cellular and tissue responses of antibody-forming organs}

Bone marrow (examined in 33 cases): It appeared cellular, but precise observation revealed that proper hematopoietic tissue was decreased in extent slightly or moderately, which was especially marked in the erythrocytic series (2 cases), granulocytic series (3 cases), megakaryocytic-thrombocytic series ( 1 case), or in more than 2 series (5 cases). Seven cases had foci of cellular decrease in number and loosening of myeloid tissue, and 2 cases had necrotic foci. In the myeloid tissue, proliferation and infiltration of plasma cells not infrequently showing Russell body formation, plasmocytoid basophilic mononuclears, atypical basophilic mononuclears, etc. were distinct (Fig. 9). It was worthy of notice that proliferation of basophilic cells with reticular arrangement at the cost of proper myeloid tissue was demonstrated in varying degrees in 25 cases (Fig. 10). In some cases hematoxylin bodies ( 2 cases) and LE transformation (1 case) were recognized.

Spleen (examined in all 37 cases): In all cases lymph follicles were atrophic in varying degrees, and the germinal centers were recognized only in a few cases. In some extreme cases original sites of lymph follicles were barely identified through the preservation of follicular arteries (Fig. 11). In 4 cases, large lymph follicles having germinal centers were encountered near the atrophic lymph follicles. In the medullary cords and periarterial lymphatic sheaths which had been already lacking lymphocytes reticulum cellular reaction including phagocytic activity (21 cases), erythro- and siderophagocytosis ( 6 cases), and increase in number of reticulum cells with vesicular cytoplasms (6 cases) were visible (Fig. 12). Proliferation and infiltration of plasma cells and plasmocytoid basophilic mononuclears (12 cases) (Fig. 11), and proliferation of cells with basophilic cytoplasms and reticular arrangement in varying degrees (14 cases) were noted. Basophilic swelling of sinus endothelial cells (2 cases), accumulation of atypical basophilic mononuclears in medullary cords and splenic sinuses (3 cases) (Fig. 13), appearance of hematoxylin bodies in lymph follicles and medullary cords (17 cases), and LE transformation ( 3 cases) were also shown.

Lymph nodes (examined in 36 cases): Mild or marked atrophy of lymph follicles was demonstrated in all cases (Fig. 14). In 9 cases decrease in number of lymphocytes or loosening of tissue was noted in the deeper zone of cortex (Fig. 14). Slight or moderate reaction of reticulum cells with phagocytic activity was recognized in the medullary cords and lymphatic sinuses in 27 cases (Fig. 14). Proliferation and infiltration of plasma cells (18 cases) and plasmocytoid basophilic mononuclears (14 cases) were seen chiefly in medullary cords, and proliferation of basophilic reticulum cells with reticular arrangement was noted in 20 cases (Fig. 15). In 2 cases atypical basophilic mononuclears appeared in medullary cords. Formation of hematoxylin bodies in 12 cases and LE transformation in 2 cases were visible.

Liver (examined in 35 cases): Intralobular accumulation of polymorphonuclear leukocytes or mononuclears (5 cases) and myeloid cells (4 cases), intralobular proliferation of reticulum cells ( 6 cases), hemosiderosis (5 cases), swelling of Kupffer's cells (8 cases), and proliferation and infiltration of lymphocytes (7 cases), plasma cells (10 cases), and plasmocytoid basophilic mononuclears ( 4 cases) and fibrosis (3 cases) in Glisson's capsules were recognized. Hepatic cell necrosis (3 cases) and peripheral or central fatty degeneration of hepatic lobules (19 cases) were also noted. Hematoxylin bodies were found in 2 cases. 
Thymus (examined in 16 cases): In 12 cases thymus was atrophic, and proliferation of spindle-shaped cells was noted in 11 cases in contrast to decrease in number of lymphocytes (Fig. 16). In the medulla reticulum cellular proliferation (1 case), and accumulation of epithelioid cells (5 cases) were also encountered. Proliferation and infiltration of plasma cells $(6$ cases) and plasmocytoid basophilic mononuclears ( 1 case), appearance of hematoxylin bodies ( 3 cases), and lymph follicle formation ( 2 cases) were recognized in the thymic tissue.

Onion-skin lesion in the arteriolar wall and surrounding tissue was visible in spleen ( 37 cases), lymph nodes ( 16 cases), and thymus ( 3 cases).

The various organ changes mentioned here demonstrated no essential difference between Group I and Group II.

\section{Correlation between glomerular changes and responses of antibody-forming organs}

As was mentioned in the paragraph of glomerular changes concurrence or coexistence of two or all of proliferative glomerulitis $(\mathrm{P})$, membranous transformation (M), and wire-loop lesion (W) throughout the kidneys or glomeruli was noted in the majority of Group I with nephrotic syndrome and in some of Group II without the syndrome. But, in a small number of the cases, almost pure occurrence of one of these types of glomerular changes was demonstrated. Accordingly, correlation between glomerular changes and responses of antibody-forming organs was at first studied on the basis of the findings of these cases.

\section{(1) Proliferative glomerulitis:}

\section{Group I}

Sapporo Med. Col. 3801 (23-year-old female): Hypoplasia of bone marrow H, and proliferation and infiltration of plasma cells and plasmocytoid basophilic mononuclears H; atrophy of splenic lymph follicles $\#$, proliferation of basophilic reticulum cells + , and macrophage reaction +; atrophy of lymph follicles of cortex of lymph nodes +, proliferation of basophilic reticulum cells $H$, and macrophage reaction + ; proliferation and infiltration of plasma cells and plasmocytoid basophilic mononuclears in Glisson's capsules + .

Niigata Univ. 123-1955 (34-year-old male): Atrophy of splenic lymph follicles $\mathrm{H}$, proliferation of basophilic reticulum cells $+\sim \mathrm{W}$, and macrophage reaction \pm ; atrophy of lymph follicles of cortex of lymph nodes + , loosening of deeper zone of cortex $\#$, proliferation and infiltration of plasma cells $H$, and macrophage reaction $H$; accumulation of mononuclears in hepatic lobules + , central fatty degeneration + , swelling and vacuolization of Kupffer's cells $\#$, and lymphocytic and plasma cellular proliferation and infiltration and fibrosis in Glisson's capsules + .

Group II

Osaka City Univ. 368 (18-year-old female): Hypoplasia of bone marrow $+\sim$ H, focal loosening or necrosis + , proliferation and infiltration of plasma cells $t$ and of plasmocytoid basophilic mononuclears + , and proliferation of basophing large lymph follicles with atrophy of splenic lymph follicles \# (occasional formation t atrophy of lymph follicles of cortex of germinal centers), and mo nodes + , loosening of deeper zone of cortex $H$, proliferation of basophilic reticulum cells $+\sim H$, and macrophage reaction $+\sim H$; proliferation and infiltration of plasma cells and plasmocytoid basophilic mononuclears in Glisson's capsules + .

Osaka City Univ. 1069 (28-year-old female): Hypoplasia of bone marrow $\# \sim H$, focal loosening or necrosis + , proliferation and infiltration of plasma cells and plasmocytoid 


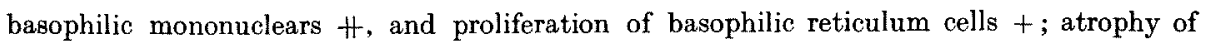
splenic lymph follicles $\# \sim \#$, fibrosis of lymph follicles + , proliferation and infiltration of plasmocytoid basophilic mononuclears + , and macrophage reaction \pm ; atrophy of lymph follicles of cortex of lymph nodes $+\sim H$, and proliferation and infiltration of plasma cells and plasmocytoid basophilic mononuclears + ; necrosis of hepatic cells + , and central fatty degeneration $t$.

\section{(2) Membranous transformation:}

\section{Group I}

Niigata Univ. 65-1962 (49-year-old female): Hypoplasia of bone marrow \#, focal loosening or necrosis + , and proliferation and infiltration of plasma cells and plasmocytoid basophilic mononuclears $\#$; atrophy of splenic lymph follicles $\#$, proliferation of basophilic reticulum cells $H \sim H$, and macrophage reaction $\mathrm{H}$; atrophy of lymph follicles of cortex of lymph nodes $H$, loosening of deeper zone of cortex + , proliferation of basophilic reticulum cells $H$, and macrophage reaction $\#$; fatty degeneration of liver + , intralobular accumulation of myeloid cells + , and proliferation and infiltration of lymphocytes and plasma cells in Glisson's capsules + .

\section{(3) Wire-loop lesion:}

\section{Group I}

Chiba Univ. 108-1962 (33-year-old male): Hypoplasia of bone marrow $\mathrm{H}$, proliferation and infiltration of plasma cells and plasmocytoid basophilic mononuclears $\#$, and macrophage reaction +; atrophy of splenic lymph follicles $\#$, proliferation and infiltration of plasmocytoid basophilic mononuclears + , proliferation of basophilic reticulum cells + , and macrophage reaction + ; atrophy of lymph follicles of cortex of lymph nodes + , proliferation and infiltration of plasmocytoid basophilic mononuclears H, and macrophage reaction + ; siderosis of liver +, and swelling of Kupffer's cells +; atrophy of thymus +, proliferation of reticulum cells in medulla + , and proliferation and infiltration of plasmocytoid basophilic mononuclears + .

From the findings described above, it was summarized that hypoplasia of bone marrow was moderate in $\mathrm{P}$, and marked in $\mathrm{M}$ and $\mathrm{W}$; atrophy of splenic lymph follicles was marked in $\mathrm{M}$ and $\mathrm{P}$, and moderate in $\mathrm{W}$; proliferation of basophilic reticulum cells was marked in $\mathrm{M}$, and macrophage reaction was marked in $\mathrm{M}$; atrophy of lymph follicles of lymph nodes was moderate in $\mathrm{M}$ and $\mathrm{W}$, and slight in $\mathrm{P}$; proliferation of basophilic reticulum cells and macrophage reaction were moderate in $\mathrm{M}$ and $\mathrm{P}$; proliferation and infiltration of plasma cells were marked in $\mathrm{P}$; and those of plasmocytoid basophilic mononuclears were moderate in $\mathrm{W}$ (Table 3). In the majority of cases having concurrence of $\mathrm{P}, \mathrm{M}$, and $\mathrm{W}$ or two of them, cellular and tissue responses of antibody-forming organs were varied in quality as well as in intensity, but they did not exceed the scope of the responses as summarized above.

\section{Addendum. Findings of infectious foci.}

Scar in palatine tonsils (Group I: 9 out of 20 cases, and Group II: 7 out of 17 cases), (tonsillectomy-Group I: none, and Group II: 2 cases), bronchopneumonia (Group I: 1 case, and Group II: 3 cases), abscesses of kidneys, etc. (Group I: 4 cases, and Group II: 3 cases), scar in appendix vermiformis (Group I: 1 case, and Group II : none), (appendectomy - Group I: 5 cases, and Group II: 5 cases), and tuberculous foci (Group I: 4 caes, and Group II : 3 cases) were found in examined cases. In 10 cases of Group I and 7 cases of Group II histological examination of palatine tonsils was not available, and in 5 cases of Group I and 
TABLE 3. Correlation between glomerular changes and responses of antibody-forming organs

\begin{tabular}{|c|c|c|c|}
\hline \multirow{2}{*}{$\begin{array}{l}\text { Responses of antibody- } \\
\text { forming organs }\end{array}$} & \multicolumn{3}{|c|}{ Glomerular changes } \\
\hline & $\begin{array}{l}\text { Proliferative } \\
\text { glomerulitis }\end{array}$ & $\begin{array}{l}\text { Membranous } \\
\text { transformation }\end{array}$ & $\begin{array}{c}\text { Wire-loop } \\
\text { lesion }\end{array}$ \\
\hline \multicolumn{4}{|l|}{ Bone marrow: } \\
\hline Hypoplasia & $+\sim H$ & H & H \\
\hline $\begin{array}{l}\text { Proliferation and infiltration } \\
\text { of plasma cells }\end{array}$ & H & $H$ & \# \\
\hline $\begin{array}{l}\text { Proliferation and infiltration } \\
\text { of plasmocytoid basophilic } \\
\text { mononuclears }\end{array}$ & $+\sim H$ & H & \# \\
\hline $\begin{array}{l}\text { Proliferation of basophilic } \\
\text { reticulum cells }\end{array}$ & + & & \\
\hline Macrophage reaction & & & + \\
\hline \multicolumn{4}{|l|}{ Spleen: } \\
\hline Atrophy of lymph follicles & $H \sim H$ & H & H \\
\hline $\begin{array}{l}\text { Proliferation and infiltration } \\
\text { of plasmocytoid basophilic } \\
\text { mononuclears }\end{array}$ & + & & + \\
\hline $\begin{array}{l}\text { Proliferation of basophilic } \\
\text { reticulum cells }\end{array}$ & $+\sim m$ & $H \sim H$ & + \\
\hline $\begin{array}{l}\text { Macrophage reaction } \\
\text { Lymph nodes: }\end{array}$ & $\pm \sim+$ & $H$ & + \\
\hline $\begin{array}{l}\text { Lymph nodes: } \\
\text { Atrophy of lymph follicles }\end{array}$ & $+\sim+$ & H & H \\
\hline $\begin{array}{l}\text { Proliferation and infiltration } \\
\text { of plasma cells }\end{array}$ & $+\sim H$ & & \\
\hline $\begin{array}{l}\text { Proliferation and infiltration } \\
\text { of plasmocytoid basophilic } \\
\text { mononuclears }\end{array}$ & + & & H \\
\hline $\begin{array}{l}\text { Proliferation of basophilic } \\
\text { reticulum cells }\end{array}$ & $+\sim H$ & H & + \\
\hline Macrophage reaction & $+\sim H$ & H & + \\
\hline
\end{tabular}

5 cases of Group II appendix vermiformis was not subjected to microscopical study. Moreover, complication of mycosis (Group I: cryptococcosis in 2 cases, and candida infection in 1 case; and Group II: cryptococcosis in 1 case, and moniliasis in 1 case) and cytomegalic inclusion disease (Group I: 1 case, and Group II: none) was also clarified.

So far as examined, the majority of cases had infectious foci such as tonsillitis, etc., which appeared related to the cellular and tissue responses of antibodyforming organs. And, mycosis or cytomegalic inclusion disease revealed in some cases seemed to be intimately related to the excessive and forced administration of adrenocortical hormones, immunosuppressive agents, etc.

\section{General Considerations and Discussions}

\section{Glomerular changes}

Among the various pathologic changes which have been said to be characteristic of SLE, wire-loop glomerular lesion was first described by Baehr et al. (1935). Muehrcke et al. (1957) pointed out the development of proliferative glomerular lesion 
in accordance with the progress of the disease, i.e., lupus nephritis besides that of membranous changes and wire-loop lesion. Fujimaki (1962) classified wire-loop lesion into 2 subtypes, type 1 with subendothelial deposition and type 2 with subepithelial deposition. Later, precise description and classification chiefly considering clinicopathological correlation were presented by Pirani and Manaligod (1966) or Pollak et al. (1966), in regard to normal kidney, glomerulitis, active glomerulonephritis, and membranous glomerulonephritis. In addition to the light microscopical observations, glomerular changes in SLE have been examined and described electron microscopically (Farquhar et al. 1957; Pollak et al. 1966; and others) and immunohistochemically (Pollak et al. 1966; Burkholder 1968; and others). In contrast to the previous reports cited above, the present study was performed from the standpoint of understanding glomerular changes as disorders or alterations of glomerular functional structure due to immunologic stimuli, and the glomerular changes were described and classified into 3 types, i.e., proliferative glomerulitis, membranous transformation, and wire-loop lesion. The present study based on histological analysis of 37 cases of SLE revealed that 20 cases with nephrotic syndrome had a tendency to occurrence of generalized, diffuse, and severe glomerular lesions, while 17 cases without this syndrome developed severe to mild glomerular lesions including those focal and segmental in nature except for 1 case without any glomerular lesions. Coexistence of two or all of proliferative glomerulitis, membranous transformation, and wire-loop lesion was noted in the majority of cases, but almost pure occurrence of one of these lesions was also encountered in a few cases.

\section{Cellular and tissue responses of antibody-forming organs}

Even Klemperer et al. (1941), who first pointed out disseminated lupus erythematosus as a systemic disease, did not describe any significant changes in bone marrow. Teilum (1948) referred to the relation between onion-skin lesion of spleen and plasma cellular proliferation. Moore et al. $(1956,1957,1959)$ described alterations of lymph nodes in this disease, which consisted of hyperplasia of lymph follicles with germinal centers, and increase in numbers of lymphocytes, reticulum cells, and plasma cells in the earlier stage, and atrophy or disappearance of lymph follicles, decrease in numbers of reticulum cells and lymphocytes, and plasma cellular proliferation not infrequently accompanied by formation of Russell bodies in the later stage. Fujimaki $(1962,1966,1970)$ described pathological histological findings of SLE in his study of collagen diseases. According to him, atrophy of lymph follicles, proliferation of plasma cells and reticulum cells appearing in lymphatic sinuses and showing vacuolar degeneration with faintly eosinophilic globules, increase in numbers of lymphogonia and lymphoblast-like immature large basophilic cells with clear nucleoli, and fibrosis of lymph nodes, and fibrosis, plasma cellular and reticulum cellular proliferation, large basophilic cell infiltration, and occasional new formation of lymph follicles of spleen were demonstrated. In the bone marrow, plasma cellular and reticulum cellular proliferation was recognized, 
but less conspicuous than that in lymph nodes and spleen. In the thymus, depletion of lymphocytic series, epithelial cell hyperplasia, plasma cellular proliferation, and an exceptional appearance of germinal centers were found. The liver showed intralobular fatty degeneration, central focal necrosis, atrophy of hepatic cells of central zone, granuloma formation, thrombosis, cellular infiltration, and proliferation of Kupffer's cells. As to the thymus in SLE, Mackay (1963) described germinal center-like formation and less well organized accumulations of epithelial cells and lymphocytes in the medulla, and MacSween et al. (1967) pointed out proliferation of plasma cells and Russell bodies in addition to formation of germinal centers.

Okabayashi $(1962,1964)$ pointed out a posthyperergic dedifferentiation of antibody-forming organs, in other words, a tendency to regression of the organoid structure to a more simplified or primitive reticular mass as a whole following their sustained hyperactivities in rabbits which developed an SLE-like disease in the course of prolonged antigenic stimulations. Okabayashi (1972) also presented data indicating development of tissue LE phenomenon in bone marrow, spleen, and liver, monotonous proliferation of reticulum cells in lymph nodes, follicular monotonous blastic cell proliferation in spleen, and monotonous proliferation of plasma cells in lymph nodes, spleen, and liver in the animals developing an SLE-like disease in the later stage of prolonged sensitization with foreign proteins. In this study, it was pointed out that immunocyte proliferation of lymph follicles resulting either in follicular LE phenomenon or in follicular dysplasia was equally accompanied by a progressive exhaustion of lymphocytes in the deep cortical or paracortical zones of lymph nodes and in the periarteriolar lymphatic sheaths of spleen.

The present study of cellular and tissue responses of antibody-forming organs in 37 cases of SLE clarified hypoplasia of myeloid tissue; atrophy of lymph follicles of spleen and lymph nodes; proliferation and infiltration of plasma cells and plasmocytoid basophilic mononuclears, and proliferation of basophilic reticulum cells at the cost of differentiated histologic organization in bone marrow, spleen, and lymph nodes; atrophy and decrease in number of lymphocytes of thymus, proliferation of spindle-shaped cells, and lymph follicle formation in a few cases. These were no essential differences in these findings between the cases with nephrotic syndrome and those without this syndrome, which were comparable in their histologic characteristics to those in rabbits developing an SLE-like disease in the later stage of prolonged immunization (Okabayashi 1962, 1964, 1972).

\section{Correlation between glomerular changes and responses of antibody-forming organs}

No reports have been presented concerning the relation between glomerular changes and responses of antibody-forming organs in SLE or lupus nephritis. Most of the contributions in this field have been available from experimental pathological studies. Dixon et al. (1961) mentioned on the basis of their studies on experimental serum sickness of rabbits that the critical factor determining whether a rabbit would develop renal disease and the type of disease developed was the amount 
of antibody the rabbit formed. According to them, the animals which responded with much antibody were likely to devlop an acute, self-limited glomerulonephritis, while those which responded with antibody barely sufficient to neutralize the antigen injected developed subacute or prolonged glomerulonephritis. In the circulation of the rabbits with glomerulonephritis of long duration, there was a daily recurring antigen-antibody reaction in the region of near antigen excess to near antibody excess which presumably led to the disease. They presented an explanation that antigen-antibody complexes formed in moderate antigen excess are capable both of reacting with complement and perhaps other serum factors on the one hand, and of being soluble and able to diffuse throughout the interstitium on the other. Kuriyama (1973), through his study of experimental chronic glomerulonephritis induced in rabbits by prolonged immunization with egg albumin, pointed out that rabbits with membranous glomerulonephritis produced antibody of low avidity and showed a sharp decline of precipitating efficiency of antibody during the course of prolonged immunization, whereas the other animals including those which developed glomerulonephritis, proliferative in character, showed a continuous synthesis of precipitating antibody of high avidity. These differences in antibody quality were apparent in 20 weeks and became greater with time. $\mathrm{He}$ considered that the formation of complexes consisting of antigen and nonprecipitating antibody might be essential for the development of membranous glomerulonephritis. As was mentioned above, experimental pathological studies, especially those of serum sickness nephritis, have revealed that proliferative glomerulitis tends to be induced in animals having sufficient formation of antibody which is provided with precipitating efficiency and high avidity, and the antigen-antibody complex is in the region of antibody excess, larger in molecular size, and accordingly susceptible to phagocytosis as was pointed out by Cochrane and Koffler (1973). On the contrary, there is a tendency that membranous transformation is induced in animals which have moderate or poor antibody formation, whereby antigenantibody complex is in the antigen excess region or in the equivalence region, smaller in molecular size and soluble, and the antibody is provided with lowered precipitating efficiency and avidity.

Fujimoto et al. (1964) clarified that Masugi nephritis induced in rats by injection of anti-rat-kidney rabbit gammaglobulin is characterized by occurrence of thickening and fibrinoid degeneration of glomerular loop walls closely resembling wire-loop lesion of human SLE in the first phase, i.e., immediately after injection of the heterologous nephrotoxic gammaglobulin and on several successive days, and paid attention to a role of anti-kidney or anti-glomerular basement membrane (antiGBM) antibody in the pathogenesis of this kind of glomerular lesion. As to induction of wire-loop-like glomerular lesion in experimental animals there have been accumulating several other studies. Nogiwa (1960) reported that severe wireloop-like glomerular lesion was induced in rabbits which had been sensitized with egg white for 120 to 140 days by injection of anti-rabbit-kidney duck serum. Okada (1963) pointed out that glomerular changes occurring in the course of prolonged 
sensitization tended to be proliferative in nature in the earlier stage and degenerative 'membranous or wire-loop-like) in the later stage. Okada (1963) and Tanaka et al. (1964) presented data indicating that a glomerular lesion resembling human wireloop lesion was induced in contralateral kidneys of rabbits by intraperitoneal inoculation of an emulsion of the animals' own unilateral kidneys following prolonged immunization with egg albumin for 162 to 165 days. In their reports production of anti-GBM antibody in the serum of rabbits and its localization in the glomerular loop walls showing wire-loop-like lesion were revealed by immunohistochemical analysis. Okabayashi (1973) described granular as well as linear deposition of immunoglobulin in the loop walls showing glomerulitis with wire-loop-like lesion resembling that of lupus nephritis in a small number of C57BL mice immunized with egg albumin for 200 days among 24 test animals. In these reports it is noteworthy that the anti-GBM antibody here demonstrated was that produced in experimental animals themselves in contrast to heterologous antiGBM antibody as seen in anti-rat-kidney rabbit gammaglobulin of Masugi nephritis. From these experimental pathological studies, it has been suggested that occurrence of wire-loop lesion is related to a role of anti-GBM antibody which is likely to be formed by the mechanism of abnormal or auto-immunization in the later stage of prolonged sensitization or prolonged antigenic stimulations.

Mellors et al. (1957) described in the study of SLE employing fluorescent microscopy a specific fluorescence occupying two, amorphous parallel, circumferential sites in the glomerular capillary walls, which consisted of an inner, granular discontinuous deposition of material and an outer, dense, continuous deposition of material apparently related to the basement membrane. It was also noted that in Fig. 5 of the paper of Koffler et al. (1969) lumpy deposits of immunoglobulins, most of which were $\gamma \mathrm{M}$ globulin, outlining glomerular tufts were described, where no granular deposits were discernible. As to the nature of lupus nephritis, especially that of wire-loop lesion appearing as eosinophilic thickening of glomerular loop wall and consisting of subendothelial deposition of fibrinoid material, however, sufficient understanding has not been obtained. In general, attentions have been paid on the significance of the role of DNA-anti-DNA complex in the pathogenesis of glomerular lesions in SLE, and an opinion that SLE is a prototype of immune complex nephritis has been offered by Koffler et al. (1971), but a role of autologous anti-GBM antibody has hardly been considered so far. One of the reasons might have been in the technical handicaps in the diagnosis of circulating anti-GBM antibodies which occur in the presence of significant titers of antinuclear antibody activity as pointed out by McPhaul and Dixon (1969).

The behavioristic features of antibody-forming organ tissues in the cases of SLE exhibiting almost purely one of the 3 types of histologic manifestations in glomeruli bear a certain resemblance to those of experimental animals which developed an SLE-like disease in the course of prolonged antigenic stimulations, and among these cases hypoplasia of myeloid tissue, atrophy of lymph follicles, proliferation and infiltration of plasmocytoid basophilic mononuclears, proliferation 
of basophilic reticulum cells, and macrophage reaction were more conspicuous in cases of membranous transformation or wire-loop lesion than in cases demonstrating proliferative glomerulitis. The latter facts appear consistent with suggestions from experimental pathological studies of Dixon et al. (1961) and those concerning prolonged antigenic stimulations. In the majority of cases of SLE coexistence or concurrence of the 3 types of glomerular changes was associated with varied histologic manifestations of antibody-forming organs though they were within the limits of responses as summarized above. The fact suggests that not only continuous or repeated antigenic stimulations of the same antigen and thereby caused localization of antigen-antibody complex in glomeruli, but several antigen-antibody complex systems either heterologous or autologous, produced by qualitative and quantitative changes of antibody formation, i.e., from hetero- to autoimmunization, play a role in the pathogenesis of glomerular lesions in lupus nephritis. In addition, a role of autologous antibody which is provided with affinity for glomeruli on the basis of immunologic factors, such as anti-GBM antibody, should not be overlooked in understanding the pathogenesis of glomerular lesions in this disease.

\section{Acknowledgment}

We are grateful to Drs. A. Okabayashi and G. Ide, Chiba University School of Medicine; Dr. M. Takamatsu, Toshima Hospital, Tokyo; Drs. T. Onoé and K. Kikuchi, Sapporo Medical College; and Drs. S. Kitamura and Y. Oonishi, Niigata University School of Medicine, for supplying the autopsy specimens used in the present study.

\section{References}

1) Baehr, G., Klemperer, P. \& Schifrin, A. (1935) A diffuse disease of the peripheral circulation usually associated with lupus erythematosus and endocarditis. Trans. Ass. Amer. Phycns., 50, 139-155.

2) Burkholder, P.M. (1968) Immunology and immunohistopathology of renal diseases. In: Structural Basis of Renal Disease, edited by E.L., Becker, Hoeber Medical Division, Harper and Row Publ., New York-Evanston-London, pp. 197-237.

3) Cochrane, C.G. \& Koffler, D. (1973) Immune complex disease in experimental animals and man. Advanc. Immunol, 16, 185-264.

4) Dixon, F.J., Feldman, J.D. \& Vazquez, J.J. (1961) Experimental glomerulonephritis. The pathogenesis of a laboratory model resembling the spectrum of human glomerulonephritis. J. exp. Med., 113, 899-920.

5) Farquhar, M.G., Vernier, R.L. \& Good, R.A. (1957) An electron microscope study of the glomerulus in nephrosis, glomerulonephritis, and lupus erythematosus. $J$. exp. Med., 106, 649-660.

6) Fujimaki, S. (1962) Pathology of collagen disease. Trans. Soc. Path. Jap., 51, 243-289.

7) Fujimaki, S. (1966) Collagen Disease. Department of Pathology, Niigata University School of Medicine, Niigata, pp. 19-67. (Japanese)

8) Fujimaki, S. (1970) Immunopathology; A note on the history of my study. Acta med. Biol., 18, 79-145.

9) Fujimoto, T., Okada, M., Kondo, Y.\& Tada, T. (1964) The nature of Masugi nephritis. Histo- and immunopathological studies. Acta path. jap., 14, 275-310.

10) Howie, J.B. \& Helyer, B.J. (1968) The immunology and pathology of NZB mice. Advanc. Immunol., 9, 215-266.

11) Klemperer, P., Pollack, A.D. \& Baehr, G. (1941) Pathology of disseminated lupus 
erythematosus. Arch. Path., 32, 569-631.

12) Klemperer, P. (1952) Pathology of systemic lupus erythematosus. In: Progress in Fundamental Medicine, edited by J.F.A., McManus, Lea and Febiger, Philadelphia, pp. 51-68.

13) Koffler, D., Agnello, V., Carr, R.I. \& Kunkel, H.G. (1969) Variable patterns of immunoglobulin and complement deposition in the kidneys of patients with systemic lupus erythematosus. Amer. J. Path., 56, 305-316.

14) Koffler, D., Agnello, V., Thoburn, R. \& Kunkel, H.G. (1971) Systemic lupus erythematosus. Prototype of immune complex nephritis in man. J. exp. Med., 134 (3, Pt. 2), 169s-179s.

15) Kuriyama, T. (1973) Chronic glomerulonephritis induced by prolonged immunization in the rabbit. Lab. Invest., 28, 224-235.

16) Mackay, I.R. (1963) Thymic "germinal centers" and plasma cells in systemic lupus erythematosus. Lancet, 2 (7309), 667-667.

17) MacSween, R.N.M., Anderson, J.R. \& Milne, J.A. (1967) Histological appearances of the thymus in systemic lupus erythematosus and rheumatoid arhtirits. $J$. Path. Bact., 93, 611-619.

18) McPhaul, J.J., Jr. \& Dixon, F.J. (1969) The presence of anti-glomerular basement membrane antibodies in peripheral blood. J. Immunol., 103, 1168-1175.

19) Mellors, R.C., Ortega, L.G. \& Holman, H.R. (1957) Role of gamma globulins in pathogenesis of renal lesions in systemic lupus erythematosus and chronic membranous glomerulonephritis with an observation on the lupus erythematosus cell reaction. J. exp. Med., 106, 191-202.

20) Moore, R.D., Weisberger, A.S. \& Bowerfind, E.S., Jr. (1956) Histochemical studies of lymph nodes in disseminated lupus erythematosus. Arch. Path., 62, 472-478.

21) Moore, R.D., Weisberger, A.S. \& Bowerfind, E.S., Jr. (1957) An evaluation of lymphadenopathy in systemic disease. Arch. intern. Med., 99, 751-759.

22) Moore, R.D., Sorenson, G.D. \& Schoenberg, M.D. (1959) Progressive cellular alterations of lymph nodes. Arch. Path., 67, 274-280.

23) Muehrcke, R.C., Kark, R.M., Pirani, C.L. \& Pollak, V.E. (1957) Lupus Nephritis. Williams and Wilkins, Baltimore.

24) Nogiwa, H. (1960) Histopathological studies of Masugi nephritis in rabbits by prolonged sensitization with egg white. J. Chiba med. Soc., 35, 1850-1861.

25) Okabayashi, A. (1962) Sensitization; An immunopathological study of infection. Trans. Soc. Path. Jap., 51, 224-242.

26) Okabayashi, A. (1964) Induction of a disease resembling systemic lupus erythematosus in later stage of prolonged sensitization in rabbits. Acta path. jap., 14, 345-371.

27) Okabayashi, A. (1972) Hematologic- and immunologic-central organs in a systemic lupus erythematosus-like disease of the rabbit experimentally induced in the later stage of prolonged sensitization. Acta haem. jap., 35, 83-100.

28) Okabayashi, A. (1973) Pathogenesis of autoimmunity; Induction of a systemic lupus-like disease in the later stage of prolonged antigenic stimulation and its pathogenetic suggestion. Clin. Immunol. (Rinsho-Men-eki), 5, 683-692. (Japanese)

29) Okada, M. (1963) Kidneys in prolonged sensitization. An experimental histopathological study. J. Chiba med. Soc., 38, 396-4l6.

30) Pirani, C.L. \& Manaligod, J.R. (1966) The kidneys in collagen diseases. In: The Kidney, edited by F.K., Mostofi \& D.E., Smith, Williams and Wilkins, Baltimore, pp. 147-203.

31) Pollak, V.E., Pirani, C.L., Jennings, R.B. \& Muehrcke, R.C. (1966) Report of the subcommittee on renal lesions of systemic lupus erythematosus (SLE). In: First Working Conference on "Nomenclature, Definition and Classification of the Pathology of Renal Diseases" (Glomerular Lesions), edited by K., Lange, Eaton Laboratories, Norwich, N.Y., pp. 1-14.

32) Tanaka, N., Nishimura, T., Tada, T. \& Okabayashi, A. (1964) Autoimmune phenomenon occurred in the course of prolonged sensitization of heterologous protein. Jap.J. exp. Med., 34, 53-57. 
33) Teilum, G. (1948) Hyperglobulinemia, periarterial fibrosis of the spleen, and the wire loop lesion in disseminated lupus erythematosus in relation to allergic pathogenesis. Amer. J. Path., 24, 409-427. 